Association for Information Systems

AIS Electronic Library (AISeL)

Wirtschaftsinformatik 2021 Proceedings

Track 17: Digital transformation \& business

models

\title{
Digital Leadership - Mountain or Molehill? A Literature Review
}

Julia Katharina Eberl

Leuphana Universität Lüneburg

Paul Drews

Leuphana Universität Lüneburg

Follow this and additional works at: https://aisel.aisnet.org/wi2021

Eberl, Julia Katharina and Drews, Paul, "Digital Leadership - Mountain or Molehill? A Literature Review" (2021). Wirtschaftsinformatik 2021 Proceedings. 5.

https://aisel.aisnet.org/wi2021/HDigitaltransformation17/Track17/5

This material is brought to you by the Wirtschaftsinformatik at AIS Electronic Library (AISeL). It has been accepted for inclusion in Wirtschaftsinformatik 2021 Proceedings by an authorized administrator of AIS Electronic Library (AISeL). For more information, please contact elibrary@aisnet.org. 


\title{
Digital Leadership - Mountain or Molehill? A Literature Review
}

\author{
Julia K. Eberl ${ }^{1}$, Paul Drews ${ }^{1}$ \\ ${ }^{1}$ Leuphana University Lüneburg, Institute of Information Systems, Lüneburg, Germany \\ Julia.Eberl@stud.leuphana.de \\ Paul.Drews@leuphana.de
}

\begin{abstract}
Despite the high relevance of digital leadership (DL) in practitioner outlets, its definition and determinants remain fuzzy, resulting in impeded DL theory development. Based on a structured literature review grounded in 96 publications, we developed a new definition of DL and a nomological determinant network. First, we provide conceptual clarity by differentiating DL from E-leadership with a definition of the former. Second, we present an inductively developed nomological network that specifies 13 DL determinants structured per the categories organizational level, individual level, and digital leader. Based on this network, we propose six future research areas, which are (1) theoretical clarity of DL as a concept, (2) measurement systems, (3) DL's impact on output variables, (4) empirical evidence about determinants of the nomological network, (5) research design extensions through further perspectives and instruments, and (6) approaches to adopt DL.
\end{abstract}

Keywords: Digital Leadership, Digital Transformation, Literature Review, Organizational Transformation, Leadership 4.0

\section{Introduction}

The year 2020 has turned out to be an unplanned milestone in the progress of digital transformation. Due to required social distancing to avoid the distribution of the Corona virus disease 2019, companies have enabled employees to work from home and adjust their business models to the resultant new demands. Automotive companies started to produce medical components, authority visits were digitalized, schools initiated remote education, and doctors offered virtual consultation hours [1], [2]. Microsoft CEO Satya Nadella summarizes the situation with, "We've seen two years' worth of digital transformation in two months" [3]. But how were these changes possible in such a short time? According to Breuer \& Szillat [4], the challenge to digital transformation is not the availability of technology, but developing new leadership competencies [5]. Most companies are now evaluating and planning the adoption of digital leadership (DL) as a leadership approach aiming at supporting the realization of digitally enabled business models by changing the behavior of leaders, organizational structures and employee 
management [6, 7]. Although DL receives great attention in practitioner outlets [8-10], there are only a few companies reporting details about methods and strategies summarized under the buzzword DL [11]. Further, in contrast to companies' high interest in adopting DL in practice, DL seems to be a rarely discussed phenomenon in leadership research. A 12-year analysis by Dinh et al. [12] of the 10 top-tier academic outlets of leadership theory in 2012 characterizes E-leadership with less than $1 \%$ representation as a nascent discipline [12]. This analysis does not thematize DL at all. From a research perspective, one could state that DL is rather a molehill than a mountain at the moment. This article seeks to address this theory-practice gap by the following research question: How is DL currently defined and conceptualized in the literature, and which research gaps can be identified?

To answer this question, we analyzed 96 contributions from the current DL literature from an inductive approach, following the recommendations by Wolfswinkel et al. [13]. Based on this analysis, we developed a definition of DL and identified its determinants in a nomological network. Moreover, we identified six future DL research areas to create a research agenda for future investigations in the field of DL.

\section{Methodology}

Our concept-based DL literature review follows the approaches of Wolfswinkel et al. [13] and Webster \& Watson [14]. To avoid a lack of documentation and ensure reliability, an additional step from Ogawa \& Malen's [15] framework was added as first step resulting in the following steps for the literature review: (1) create an audit trail documenting the reviewers' steps, (2) define the research scope, (3) search for literature, (4) select appropriate publications based on step (2), (5) analyze the selected literature, and (6) present the results. The remainder of this section describes this approach's application in this DL literature review.

First, an audit trail was initiated in a digital notebook. The purpose of this documentation is to provide evidence for all steps and thereby increase traceability [16]. The audit trail consists of the above-mentioned steps and documents the results. Moreover, it reflects decisions that were taken, such as inclusion and exclusion criteria, databases, and papers.

The literature review's purpose, as structured by Cooper's taxonomy [17], is to identify the central issues in DL research by focusing on research outcomes in the commercial sector by analyzing representative contributions. As such, the authors took a neutral perspective to conceptually organize the literature review for a general scholarly audience.

Based on that purpose, we gained an initial overview of the current state of the literature from March 2020 to the end of May 2020. This overview showed that DL is highly thematized in practical papers, as well as in Information Systems (IS) research. Hence, the literature search included general databases (Google Scholar, Emerald Insights, Science Direct) in addition to specialist sources focusing on IS (Association for Information Systems (AIS) Library), leadership (Elsevier, PsycINFO, Web of Science), and business administration (Business Source Premier via EBSCO, 
ABI/INFORM). To integrate a practical perspective, the database searches included non-peer-reviewed articles, and forward and backward searches were conducted. Furthermore, pertinent journals (The Leadership Quarterly, Journal of Management, Information \& Organization, Journal of MIS) were manually examined for the latest publications to locate DL in overall leadership and IS research. The search was based on the keywords "digital leadership," "digital leader," "digitalization AND leadership," "leadership 4.0," and "leader 4.0," filtering out work not mainly focusing on DL in the title or abstract. The resulting initial sample size of $n=287$ papers from 1997 to 2020 (37 of the 287 papers stemmed from the forward and backward search [14]) was reduced by applying exclusion criteria as shown in Table 1 . In this way, we gathered a literature collection of $n=96$ works from 2000 to 2020 .

Table 1. Exclusion criteria and sample size

\begin{tabular}{lll}
\hline Exclusion criteria & $\begin{array}{l}\text { Sample size (n) after } \\
\text { applying exclusion criteria }\end{array}$ \\
\hline $\begin{array}{l}\text { Non-commercial context (e.g. public sector, } \\
\text { education) }\end{array}$ & $\mathrm{n}=192$ \\
$\begin{array}{l}\text { Missing DL focus in the body of the text } \\
\text { No detailed description of DL aspects or outcomes }\end{array}$ & $\mathrm{n}=127$ \\
$\begin{array}{l}\text { Artifacts of similar content, research type, and } \\
\text { references were scanned and consolidated to the }\end{array}$ \\
\begin{tabular}{l} 
most relevant papers \\
\hline
\end{tabular}
\end{tabular}

The review process was conducted in four steps, starting with a template to collect general information about the articles, such as publishing outlet, date, industry and context, paper type (practitioner outlet/research paper), research question, and design (observational, experimental, quantitative/qualitative), as well as a summary of the central statements and methods. Second, we inductively created codes about DL and added these codes to every paper in the review. We evaluated the created literature database regarding the used codes and reflected outcomes. Third, we developed determinants and their relationships based on the collection of codes. Lastly, we summarized the determinants by their influence on the categories digital leader, organizational level, and individual level.

\section{$3 \quad$ Findings}

In the following section 3.1, we increase clarity on DL based on the current state of the literature by analyzing the concept's definition and creating a nomological network of 13 DL determinants divided into three categories. Afterward, we thematize the determinants $(3.2-3.4)$ and identify six future research areas (3.5). 


\subsection{Definition and Nomological Network}

The analysis shows that within the 36 publications that explicitly discuss the definition of DL, definitional fuzziness exists in the following three aspects.

First, the relation between E-leadership and DL is unclear in the current literature state. Avolio, Kahai, and Dodge [18] define E-leadership as "a social influence process mediated by advanced information technologies (AIT) to produce a change in attitudes, feelings, thinking, behavior and/or performance of individuals, groups, and/or organizations" [19]. Therefore, E-leadership will not change the fundamentals of business but the execution of business as supported by technology [20]. Klus \& Müller [21], meanwhile, use E-leadership and DL as synonyms.

Second, the analyzed literature provides abstract definitions of DL [11], [19-21] that impede the differentiation between E-leadership and DL. For example, Meffert \& Swaminathan [22] define DL as an approach suitable for the digital age, which is similar to El Sawy [11], who understands "doing the right things for the strategic success of digitalization for the enterprise and its business ecosystem" as DL.

The third finding speaks against using E-leadership and DL as synonyms, as DL is more extensive than E-leadership. While E-leadership uses technology to support existing business [20], DL is an instrument to achieve the target of digitally enabled business models [6], [7], digital organization [6], [23], and employee management [9], [24]. To influence these dimensions, DL adjusts different determinants in the company [11], [25], [26].

We seek to overcome the current lack of a comprehensive DL definition by providing our own, which is grounded in the literature review's results and the three aspects discussed above:

Digital leadership is a complex construct aiming for a customer-centered, digitally enabled, leading-edge business model by (1) transforming the role, skills, and style of the digital leader, (2) realizing a digital organization, including governance, vision, values, structure, culture, and decision processes, and (3) adjusting people management, virtual teams, knowledge, and communication and collaboration on the individual level.

This definition includes three important parts. First, it specifies DL's purpose, which is establishing customer-centric business models by using technology. In contrast to Eleadership, which uses technology as a mediator, DL's outcome is the usage of digitally enabled business models. Second, the definition identifies the determinants influenced by DL to meet the objective. Third, it concerns the digital leader, who steers the different determinants to serve the purpose.

Based on the literature analysis, we created a DL nomological network that provides an overview of the concept's determinants (see Figure 1). The network is structured per the categories of influence on the organization, the individual, and the digital leader, such as people management influences the individual. The network is comprised of determinants and adds relations based on the codes identified in the review process. 


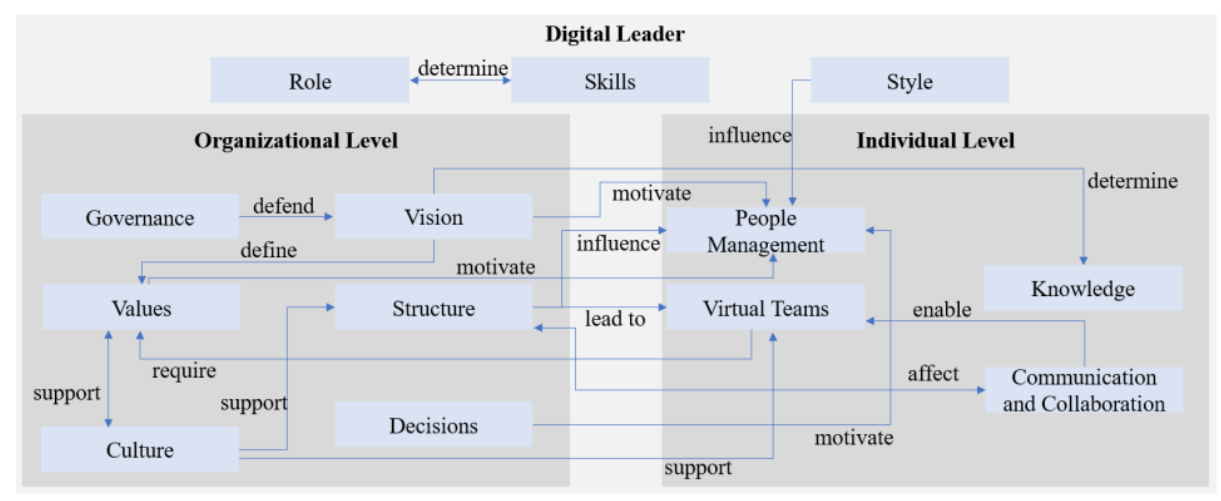

Figure 2. Determinants of DL

\subsection{Digital Leader}

The current state of the literature mentions skills, roles, and leadership styles as important characteristics of a digital leader. Most of the reviewed literature (53\%) focuses on skills, whereas roles and leadership styles are only represented in $27 \%$ of the analyzed papers.

Role. Several articles $(n=33)$ describe the changed role of the leader, even though unclarity exists about who this leader is. This lack of clarity impedes defining DL. Most articles focus on digital leaders in disciplinary roles [27], [28-31]. For instance, according to a study by Deloitte Digital GmbH [32], 70\% of companies that meet digital transformation's success criteria have a single responsible person in place: the Chief Digital Officer (CDO). However, the CDO role harbors the danger of a disconnected digital unit. Therefore, LEGO emphasizes the importance of a CDO by suggesting a digital leader as CDO in every business unit [11]. Nevertheless, it needs to be questioned if one Digital Leader in the role of the CDO per company or per business unit is capable to achieve the goal of DL. Yet, a minority of the analyzed papers point out that every employee must act as a digital leader, as followers take over entrepreneurial responsibilities for the company [27], [33]. However, this change is rarely thematized in the analyzed literature $(\mathrm{n}=2)$. Still, the publications show that in contrast to traditional leaders who act from a command and control perspective [34] and as the lone decision-makers with hierarchical distance from their followers [35], a digital leader connects with a team as a mentor, coach, talent builder, and learning guide who does not require disciplinary power [24], [34], [36], [37]. The digital leader needs the skills to be a visionary [38] who acts as a role model for employees [25], [28-30].

Style. The leadership style of a digital leader is rarely discussed in the literature (n $=5$ ). Because of the relevance of authentic, transformational, and transactional leadership styles in DL, Prince [39] comes to the theoretical conclusion that DL overlaps with authentic, transactional, and transformational leadership. Therefore, transactional and transformational leadership have a direct influence on digital skills and digital strategy, whereas authentic leadership's impact is limited to digital skills 
[39]. The authentic leadership style of a digital leader drives employees to develop innovations [39] and engage in participative decision-making [40]. However, a transactional approach provides processes to meet organizational requirements, as employees are motivated to be digitally savvy and adopt new technologies with rewards [41]. A digital leader's transformational leadership style is a consultative and delegating approach [42] that inspires followers to be innovative [43].

Skills. Visionary, digitally savvy, collaborative, adaptable, and motivating are the most mentioned skills of a digital leader [21], [23], [44-46] in the literature. These five skills result from two types of digital leader skillsets existing in the literature: (1) empirical papers suggest a small skillset focusing on agility, openness and innovative thinking [23], [44], [45]. (2) In contrast to that, the published reviews present a high amount of skills categorized as digital business, general mindset, and social attitude [21], [46]. However, these extensive skillsets blur the focus on the distinctive skills of a digital leader required to flexibly adjust to a broad variety of digitalization tasks.

\subsection{Organizational Level}

Vision. The definition of a vision is the center of DL on the organizational level, as it is highly connected to other determinants (see Figure 1). Although the realization of the vision is formulated in the strategy, which is mentioned in the analyzed literature, neither strategy nor the relation between strategy and vision are described [47]. As the digital world is constantly changing, agility could have replaced the need for long-term plans as summarized in a strategy. However, the analyzed literature does not give evidence on why strategy is not a DL determinant.

Still, there is evidence that digitally successful companies more often have a digital vision than others [48]. A vision should be clearly formulated, aspiring, holistic, sustainable, inspiring, convincing [22], [45], and define the company's value and purpose [49], [50]. Inconsistency exists about the creation of a vision by a leader or staff as a living artifact [49], [51]. A vision serves four purposes: (1) to act as a roadmap and define the direction of change [52], [53] and the knowledge required for that [29], (2) to motivate employees, (3) to orient which digital trends are relevant to serving the vision [4], [24], [29], [35], [42], [54], [55], and (4) to lead an agile organization when strict processes are not in place, as collaboration is supported by employees' strongly identifying with the vision [56].

Governance. Although corporate governance is well known to prevent innovations and slow down decisions in practice [34], [50], 13\% of the analyzed literature includes governance as part of DL to define a boundary in which the digital vision can be realized [57]. Therefore, governance defends the vision by evaluating investments and activities according to their contribution to the vision [48], [58]. Even though the frequency is unclear, the analyzed literature emphasizes two different governance functions: (1) DL requires governance for data privacy [59], [60] and information quality [61], and (2) innovation committees are staffed with the most innovative employees to drive and align strategic innovations [7], [62]. However, a knowledge gap regarding technology governance, values, and risk exists within governance board members [63]. 
Values. The existing literature mentions the following values in the context of DL:

Table 2. Values in the context of DL

\begin{tabular}{ll}
\hline Values & References \\
\hline Diversity and inclusion & {$[8],[34],[64],[65]$} \\
Sustainability & {$[33],[39],[50],[66],[67]$} \\
Trust & {$[11],[19],[33],[34],[42],[45],[51]$,} \\
& {$[56],[61],[66],[68-71]$} \\
Freedom to experiment & {$[53],[64]$} \\
Openness & {$[11],[19],[24],[33],[44],[51],[54]$,} \\
& {$[64],[69],[72-74]$} \\
Transparency & {$[6],[33],[42],[49],[51],[57],[64],[73]$,} \\
& {$[75]$} \\
Employee focus & {$[11],[6],[33],[35],[48],[49],[52],[57]$,} \\
& {$[59],[65],[76],[77]$} \\
Customer centricity & {$[4],[33],[36],[45],[49],[51],[54],[56]$,} \\
& {$[59],[76-84]$} \\
\hline
\end{tabular}

However, the impact of values on a company's vision, as common guidance for globally distributed teams [64], [72] and to motivate employees when the companies' values match their employees' values [53] is not analyzed. When it comes to the definition of values, Bolte et al. [53] show that within start-ups, the values of openness, transparency, trust, and employee focus are more frequently represented than in other companies. Meanwhile, especially older companies focus on traditional values, such as thoroughness and precision [8]. Moreover, the question arises if all values mentioned have dependencies to DL (like freedom to experiment) or if they are general values of companies like sustainability.

Culture. As culture is a norm that transports companies' philosophies and policies to employees and customers, culture is discussed in $51 \%$ of the analyzed literature in the context of supporting network structures and virtual teams, as well as being aligned with values [85]. As such, DL has the objective to create an innovative [23], [30], [42], [52], [57], [79], [81], [86], positive [85], and collaborative [23], [29], [87] culture. Culture sets technology first, not legacy, [52], [80], and encourages employees to take risks [23], [39], [50], [56] and fail [19], [53], [57], [88], [89]. Although some papers in the literature declare culture as a mandatory determinant of DL, the dependency of DL on culture is disputed as $49 \%$ of the literature does not cover culture at all. Another important aspect of culture is the mindset of digital leaders and employees. DL emphasizes a digital [24], [33], [52], [83], experimental [11], [54], and growth-centered mindset that encourages employees to be curious, think differently, and continuously expand their knowledge [39], [90] resulting in the employees feeling more empowered and committed [19]. Yet, the literature does not mention how this culture and the mindset can be realized.

Decisions. DL requires decision processes that enable the company to act nimbly and fast [4], [27], [28], [72]. Therefore, decisions can be made with incomplete 
information [34], [52], [89], including new types of data, such as unstructured and social media data, to obtain a predictive perspective and minimize uncertainty by taking into account predictive simulations, virtual reality, and big data correlations [33], [34], [52], [54], [55], [59], [81], [91-93]. Besides these rational, data-based decisions [54], papers also report that the final decision is influenced by intuition [34], [51], [59], [72].

Moreover, the literature focuses on people who have the authority to make decisions. Because of the complexity and required knowledge for decision-making, authority frequently shifts from the leader to employees and cross-functional teams [11], [24], [46], [48], [65], [73], [89], [92], [94], [95]. As such, employees are more motivated by the empowerment to participate in decisions and expect more success [7]. This authority emphasizes the dependency to the role of the digital leader as every employee needs to act as a digital leader. Notwithstanding the positive impacts on motivation, agility, and potential success, the literature also reports that the final decision is usually made by the leader [34], [35], [69].

Structure. There is a consensus in the literature that digital leaders need to reduce existing hierarchical structures [35], [39], [53], [56], [59], [72-74], [84] to increase employees' motivation [53], [93], innovations [65], and agility when reacting to changing customer demands. People work in highly connected, dynamic, and temporary networks that are established for a specific purpose and time [19], [22], [23], [31], [33], [50], [51], [65], [71], [72], [74], [84], [85], [89], [90], [96], [97]. Accordingly, work in networks needs to be supported by agile methods and approaches, such as design thinking and prototyping [8], [10], [24], [26], [55], [84], [94].

In contrast to the consensus regarding hierarchy and agile methods, the reviewed literature presents different opinions when it comes to DL's organizational positioning. A digital unit within the organization is implemented to drive innovation, whereas classical IT is responsible for operating legacy systems [7], [31], [98]. This concept leads to a disconnected digital unit and does not drive change in the overall company [33], [82], [99]. Therefore, Trompenaars \& Woolliams [81] recommend harmonizing the strengths of traditional and digital units.

\subsection{Individual Level}

People Management. People management, employee motivation, and rewards are highly influenced by flexible network structures, vision, and employee empowerment to make decisions [7], [31], [34], [94]. Digital leaders support employees in selfmanagement and career development [26], [33], [53], [55]. As such, digital leaders act as coaches and give feedback independent from formal authority [90]. Furthermore, DL needs to promote employees' intrinsic motivation by supporting their identification with the company's values [7], [46], [51], [56], [62], improving the alignment of life and work [65], and contributing to personal well-being [77]. In addition, extrinsic motivation can be triggered by supporting standardized tasks with gamification [7] and performance indicators [60]. The literature also reports targets for teamwork [94], democratized salary definition, and employee hiring and evaluation [66].

Knowledge. Because of technology's high rate of change, companies have to constantly adjust their workforce's capabilities, as manifested by Lego with the mantra 
"Hire for a Career, not a Job" [11]. Moreover, knowledge is an essential factor in providing digital business models [74]. That is why DL establishes a culture of lifelong learning [33], [38], [50], [53], [57], [72], [89], [95], [100], including professional and soft skills [50]. To support learners and motivate employees, formats need to change to user-centric, mobile experience, including gamification [95]. Further, motivation is created by a digital leader who acts as an idol for learning [76]. Besides these learning methods, according to Bolte et al. [53], the coaching format is not as successful in large companies as in start-ups. Overall, learning has a significant impact on DL's success [101] although the used learning formats and their impact is not thematized.

Virtual Teams. Working in networks leads to the demand for creating virtual teams for specific projects [65]. Furthermore, increased employer attractiveness, motivation, agility, and creativity can be achieved by enabling employees to work where, when, and how they want [65], [102]. Hence, leading virtual teams is an important determinant of DL. The digital leader needs to coach employees regarding cultural and ethical sensibility to enable teamwork in globally distributed and heterogenous teams [24], [51], [57], [60], [64], [68], [72], [96]. However, leading individuals in a virtual team is rarely mentioned in the reviewed literature. Meetings between leaders and employees are important to discussing feedback and addressing employees' situations [10], [72], [103]. Especially more passive employees need coaching on participating in virtual teams and written communication to avoid isolation [19], [34].

Collaboration and Communication. Another DL determinant is collaboration and communication, which enables a collaborative culture, virtual team, and network structure [50], [59], [64]. For this reason, extended collaboration brings agile network structures to life when people are motivated to collaborate across functions and organizations to find the right knowledge to work together [48], [50], [54], [56], [57], [97], [98], [100], [104]. In addition, digital leaders use social media platforms to engage across companies [24] with customers, partners, employees, and other stakeholders [4], [20], [33], [53], [54], [73], [75], [102], [104]. Compared to other determinants of DL as described in this paper, the impact of collaboration and communication on faster reaction to customer requests [38], [56], higher managerial effectiveness [64], quantitative productivity improvements [64], and increased digital leader organizational legitimacy is non-controversial. However, the success of communication does not only depend on quantity but also on the content which has not been studied so far. Moreover, Bolte et al. [53] show in a survey-based study that the leader's and the follower's perspectives on communication highly diverge, as the leader observes more communication activities than the follower receives.

\subsection{Future Research}

This literature review contributes to the understanding of the determinants of DL, including the digital leader, the organizational level, and individual level. We can see that initial steps in practice and research have been taken, though we now identify six areas that require further attention in upcoming research. 
First, a common understanding of DL and its comparison to other leadership styles should be developed, as the relevant skills of a digital leader can also be found in other leadership approaches [44], [46]. Hence, theoretical advancements can be made by defining DL and advancing its characteristic features. Moreover, DL's differentiation from and overlap with authentic, transformative, and transformational leadership should be analyzed [39].

Second, these theoretical advancements should be supported by developing a DL measurement system. Based on a questionnaire, different facets of DL and adoption stages can help leaders identify their DL status.

Third, besides measuring DL's status in a company, DL's impact on output variables is unclear. Although Weill \& Wörner [80], Valentine \& Steward [63] and Rüth \& Netzer [105] identify DL's positive impact on agility, innovativeness, and customer experience, the determinants of DL leading to these and other outcomes need to be further analyzed.

Fourth, missing evidence also exists in this paper's nomological network. More empirical research is required to evaluate and improve the set of determinants and the impact of DL on a company's intended outcome.

Fifth, to get the above-mentioned results, higher variation in research and stronger survey designs are needed. This starts with the research participants. The current state of the literature is based on quantitative surveys and interviews with digital leaders, as in the analyzed literature, only Bolte et al. [53] includes followers' perspectives. To avoid the influence of context variables, further research instruments, such as online panels or student samples, can be used to extend the understanding of DL.

Sixth, in addition to endeavors that seek to improve the understanding of DL, additional research is required regarding DL's adoption. To accomplish this, three approaches can be combined: First is conducting a longitudinal survey and interviews within the same research group during their transition to DL. Second, two independent units of the same company, with one unit transitioning to DL, can be compared regarding the differences in their determinants and outcomes. Third, a pioneering industry can be identified to analyze the realization, impact, and lessons learned along the DL journey.

\section{Conclusion and Limitations}

Is DL a molehill or a mountain? The journey to finding the answer to this question led us through a review of DL's different definitions, resulting in the development of a new definition for the term. Although Prince [39], Valentine [58], and Klus \& Müller [21] analyze single determinants of DL, this literature review extracted the 13 most relevant determinants from the 96 reviewed articles and summarized the relationships of these determinants in a nomological network for the first time. The determinants in this network are structured per (1) the digital leader's skills, roles, and leadership style, (2) DL's organizational level, including company vision, values, culture, governance, decisions, and structure, and (3) DL's individual level, consisting of people management, knowledge, virtual teams, as well as collaboration and communication. 
Based on these results, we conclude that DL is more than a molehill, as the analyzed literature describes companies' requirements for DL and its determinants. However, to become a mountain, DL's fuzzy definition and implementation, as well as its determinants, need to be clarified by further research, as identified in section 3.5.

This article has three limitations: (1) Despite the systematic research approach to increase objectivity, the analysis was conducted by one researcher; (2) DL research is present internationally; the current literature review only covers the most relevant German and English publications, other languages are not considered; and (3) DL is quickly evolving; because of that, further papers could have been published during the publication process of this literature review.

Although DL is important in practice, it is at an early research stage and requires further investigations, as described in section 3.5.

\section{References}

1. Wuest, T., Kusiak, A., Dai, T., Tayur, S. R.: Impact of COVID-19. ORMS Today 47, 1-16 (2020)

2. Greenhalgh, T., Wherton, J., Shaw, S., Morrison, C.: Video consultations for covid-19. BMJ 368, 1-2 (2020)

3. Spataro, J.: 2 years of digital transformation in 2 months, https://www.microsoft.com/enus/microsoft-365/blog/2020/04/30/2-years-digital-transformation-2-months/ (Accessed: 12.07.2020)

4. Breuer, S., Szillat, P.: Leadership and Digitalization contemporary approaches towards leading in the modern day workplace. Dialogue 1, 24-36 (2019)

5. Horlacher, A., Hess, T.: What Does a Chief Digital Officer Do? Managerial Tasks and Roles of a New C-level Position in the Context of Digital Transformation. 49thHawaii International Conference on System Sciences, Waikoloa Beach, 5126-5135 (2016)

6. Oberer, B., Erkollar, A.: Leadership 4.0: Digital Leaders in the Age of Industry 4.0. Int. J. Organ. Leadersh. 7, 404-412 (2018)

7. Petry, T.: Digital Leadership - Unternehmens-und Personalführung in der Digital Economy. In: Petry, T. (ed.) Digital Leadership, pp. 21-82. Haufe Lexware GmbH, Freiburg im Breisgau (2016)

8. Buhse, W.: Digital Leadership bei der Robert Bosch GmbH. Wissensmanagement 6, 14 15 (2014)

9. Jenewein, T.: Digital Leadership bei SAP. In: Petry, T. (ed.) Digital Leadership, pp. 373384. Haufe Lexware GmbH, Freiburg im Breisgau (2016)

10. Neun, W.: Digitale Transformation und Agilität in der Praxis. Springer, Wiesbaden (2020)

11. El Sawy, O. A., Kræmmergaard, P., Amsinck, H., Lerbeck Vinther, A.: How LEGO Built the Foundations and Enterprise Capabilities for Digital Leadership. MIS Q. Executive 15, 141-166 (2016)

12. Dinh, J. E., Lord, R. G., Gardner, W. L., Meuser, J. D., Liden, R. C., Hu, J.: Leadership theory and research in the new millennium: Current theoretical trends and changing perspectives. Leadersh. Q. 25, 36-62 (2014) 
13. Wolfswinkel, J. F., Furtmueller, E., Wilderom, C. P.: Using grounded theory as a method for rigorously reviewing literature. Eur. J. Inform Syst. 22, 45-55 (2013)

14. Webster, J., Watson, R. T.: Analyzing the Past to Prepare for the Future: Writing a Literature Review. MIS Q. 26, xiii-xxiii (2002)

15. Ogawa, R. T., Malen, B.: Towards rigor in reviews of multivocal literature: Applying the exploratory case method. Rev. Educ. Res. 61, 265-286 (1991)

16. Randolph, J.: A Guide to Writing the Dissertation Literature Review. Research and Evaluation 14, 1-13 (2009)

17. Cooper, H.M.: Organizing knowledge syntheses: A taxonomy of literature reviews. Knowl. Soc. 1 (1988)

18. Avolio, B. J., Kahai, S., Dodge, G. E.: E-Leadership: implications for theory, research and practice. Leadersh. Q. 11, 615-668 (2001)

19. Balan, A. C., Cavendish, K.: Leadership in the Digital and Social Era-A Theoretical Review and Digital Gamification for Employee Development. School of Economics and Management, Lund University

20. DasGupta, P.: Literature Review: e-Leadership. ELJ 4, 1-36 (2011)

21. Klus, M.F., Müller, J.: Identifying leadership skills required in the digital age. Westfälische Wilhelms-Universität, Münster (2018)

22. Meffert, J., Swaminathan, A.: Leadership and the urgency for digital Transformation. Leader to Leader 88, 44-49 (2018)

23. Kane, G. C., Nguyen Phillips, A., Copulsky, J., Andrus, G.: How Digital Different is(n't) different. MIT Sloan Manag. Rev. 60, 34-39 (2019)

24. Eggers, B., Hollmann, S.: Digital Leadership - Anforderungen, Aufgaben und Skills von Führungskräften in der "Arbeitswelt 4.0". In: Keuper, F., Schomann, M., Sikora, L. I., Wassef, R. (ed.) Disruption and Transformation Management, pp. 43-68. Springer Fachmedien, Wiesbaden (2018)

25. Van Dick, R., Helfritz, K. H., Stickling, E., Gross, M., Holz, F.: Digital Leadership. Personalwirtschaft 8, 1-23 (2016)

26. Buhse, W.: Changing the Mindset: Die Bedeutung des Digital Leadership für die Enterprise 2.0-Strategieentwicklung. In: Lembke, G., Soyez, N. (ed.) Digitale Medien im Unternehmen, pp. 237-252. Springer, Berlin Heidelberg (2012)

27. Rassek, A.: Digital Leadership: Was zeichnet einen Digital Leader aus?, https://karrierebibel.de/digital-leadership/ (Accessed: 11.07.2020)

28. Wade, M., Obwegeser, N.: How to Choose the Right Digital Leader for Your Company. MIT Sloan Manag. Rev. 60, 1-4 (2019)

29. Gouveia, L.B.: Emerging alternatives to leadership and governance for a digital ecosystem. 15th European Conference on Management Leadership and Governance, Porto, 1-43 (2019)

30. Underwood, C.: Developing leadership roles for a digital age. Strategic HR Review 18, 233-234 (2019)

31. Zeichhardt, R.: E-Leader, CDOs \& Digital Fools - eine Führungstypologie für den digitalen Wandel. In: Keuper, F., Schomann, M., Sikora, L. I., Wassef, R. (ed.) Disruption and Transformation Management, pp. 3-21. Springer Fachmedien, Wiesbaden (2018) 
32. Deloitte Digital GmbH: Überlebensstrategie "Digital Leadership", https://www2.deloitte.com/de/de/pages/technology/articles/survival-through-digitalleadership.html (Accessed: 27.06.2020)

33. Borowska, G.: Digital leadership for digital transformation. Contemporary Economy Electronic Scientific Journal 10, 11-19 (2019)

34. April, K., Dalwai, A.: Leadership Styles Required to Lead Digital Transformation. Effective Executive 22, 14-45 (2019)

35. Ehmann, B.: Quick Guide Agile Methoden für Personaler. Springer Fachmedien, Wiesbaden (2019)

36. Bosch, U., Hentschel, S., Kramer, S.: Digital Offroad: Erfolgsstrategien für die digitale Transformation. Haufe-Lexware, Freiburg im Breisgau (2018)

37. Zupancic, T., Verbeke, J., Achten, H., Herneoja, A.: Digital Leadership. 34th eCAADe Conference 1, Oulu, 63-68 (2016)

38. Krug, P., Weiß, M., Lang, J.: Digital Leadership: Führung im Zuge der digitalen Transformation. Wirtschaftsinformatik \& Management 10, 48-59 (2018)

39. Prince, K.A.: Digital leadership: transitioning into the digital age. James Cook University, Queensland (2018)

40. Anderson, H. J., Baur, J. E., Griffith, J. A., Buckley, M. R.: What works for you may not work for the (Gen) Me: Limitations of present leadership theories for the new generation. Leadersh. Q. 28, 245-260 (2017)

41. Akinbode, A. I., Shuhumi, S. R. A.: Change management process and leadership approaches. Int. J. Soc. Sci. 4, 609-618 (2018)

42. Kieser, H.: The influence of digital leadership, innovation and organisational learning on the digital maturity of an organisation. University of Pretoria, Pretoria (2017)

43. Judge, T. A., Bono, J. E.: Five-factor model of personality and transformational leadership. J. Appl. Psychol. 85, 751-765 (2000)

44. Pabst von Ohain, B.: Leader Attributes for Successful Digital Transformation. Fortieth International Conference on Information Systems, Munich, 1-17 (2019)

45. Promsri, C.: The Developing Model of Digital Leadership for a Successful Digital Transformation. GPH - Int. J. Bus. Manag. 2, 1-8 (2019)

46. Klein, M.: Leadership Characteristics in the era of digital transformation. Business \& Management Studies 8, 883-902 (2020)

47. Mintzberg, H.: The Strategy Concept I: Five Ps for Strategy. California Management Review 30, 11-24 (1987)

48. Westerman, G., Bonnet, D., McAfee, A.: Leading digital: turning technology into business transformation. Harvard Business Press, Cambridge (2014)

49. Fisk, P.: The Making of a Digital Leader. BSR 13, 43-50 (2002)

50. Tiekam, A.: Digital leadership skills that South African leaders need for successful digital transformation. University of Pretoria, Pretoria (2019)

51. Khan, S.: Leadership in the digital age: A study on the effects of digitalisation on top management leadership. Stockholm University, Stockholm (2016)

52. Aron, D., Waller, G., Weldon, L.: Flipping to Digital Leadership: The 2015 CIO Agenda, https://www.gartner.com/en/documents/2864717/flipping-to-digital-leadership-the-2015cio-agenda (Accessed: 04.03.2020) 
53. Bolte, S., Dehmer, J., Niemann, J.: Digital Leadership 4.0. Acta Technica Napocensis 61, 637-646 (2018)

54. Chadha, S.: Digital Leadership - Leveraging the uniqueness of Digital. Human Capital 3, 24-31 (2019)

55. Afandi, W.: The Role Of Strategic Leadership In Digital Transformation Process. Int. J.

Recent Res. Appl. Stud. 33, 19-22 (2017)

56. Doyé, T.: Digital Leadership. In: Fend, L., Hofmann, J. (ed.) Digitalisierung in Industrie-, Handels- und Dienstleistungsunternehmen, pp. 207-224. Springer, Wiesbaden (2020)

57. Crummenerl, C., Kemmer, K.: Digital Leadership - Führungskräfteentwicklung im digitalen Zeitalter, https://www.capgemini.com/consulting-de/wpcontent/uploads/sites/32/2017/08/14-10-16_digital_leadership_v11_web_17102016.pdf (Accessed: 12.07.2020)

58. Valentine, E.: Enterprise Business Technology Governance: New Core Competencies for Boards of Directors in Digital Leadership. Queensland University of Technology, Brisbane (2016)

59. Sahyaja, C., Sekhara Rao, K. S.: New Leadership in the digital era - a conceptual study on emotional dimensions in relation with intellectual dimensions. Int. J. Civ. Eng. Technol. 9, 738-747 (2018)

60. Antoni, C.H., Syrek, C.: Digitalisierung der Arbeit: Konsequenzen für Führung und Zusammenarbeit. Gr. Interakt. Org. 48, 247-258 (2017)

61. Outvorst, F., Visker, C., de Waal, B. M.E.: Digital Leadership - As the Only Way to Survive a Changing Digital World? 14th European Conference on Management, Leadership and Governance, Utrecht, 300-306 (2018)

62. Ahrendts, A.: Digital Leadership. An interview with Angela Ahrendts, CEO of burberry, https://www.capgemini.com/wpcontent/uploads/2017/07/DIGITAL_LEADERSHIP_An_interview_with_Angela_Ahrend ts.pdf (Accessed: 10.07.2020)

63. Valentine, E., Stewart, G.: Enterprise Business Technology Governance: Three Competencies to Build Board Digital Leadership Capability. Proceedings of the 48th Annual Hawaii International Conference on System Sciences, Waikoloa Beach, 45134522 (2015)

64. Kraft, M.H.G.: How to lead with digital media effectively? A literature-based analysis of media in a E-leadership context. J. Eco. Dev. Environ. People 8, 42-53 (2019)

65. Kolzuniak, J.: Digital Leadership - Entwicklung eines Führungsmodells für effizientes Agieren in einer digital vernetzten Arbeitsumgebung im Vertrieb der Geschäftsbanken. Deutsches Institut für Bankwirtschaft - Schriftenreihe Band 14b, 1-52 (2017)

66. Lenz, U., Grützmacher, P.: Was bin ich (noch), und was sollte ich sein? Die Auswirkungen der Digitalisierung auf die Rolle der Führungskraft. In: Von Au C. (ed.) Führen in der vernetzten virtuellen und realen Welt, pp. 1-18. Springer, Wiesbaden (2018)

67. Asri, A. A. S. M. A. N., Darma, G. S.: Revealing the digital leadership spurs in 4.0 industrial revolution. Int. J. Bus. Eco. Manag, 3, 93-100 (2020)

68. Lindner, D.: Studie 3: Digital Leadership in KMU - Was sagen Führungskräfte? In: Lindner, D. (ed.) KMU im digitalen Wandel, pp. 29-36. Springer, Wiesbaden (2019) 
69. Meier, C., Sachs, S., Stutz, C., McSorley, V.: Establishing a digital leadership barometer for small and medium enterprises (SME). Proceedings of the MKL and TIIM International Conference, Lubin, 103-109 (2017)

70. Sievert, H., Scholz, C.: Engaging employees in (at least partly) disengaged companies. Results of an interview survey within about 500 German corporations on the growing importance of digital engagement via internal social media. Public Relations Review 43, 894-903 (2017)

71. Bersin, J.: Digital Leadership Is Not an Optional Part of Being CEO. Harvard Business Review 12, 2-4 (2016)

72. Schwarzmüller, T., Brosi, P., Duman, D., Welpe, I. M.: How Does the Digital Transformation Affect Organizations? Key Themes of Change in Work Design and Leadership. Management Revue 29, 113-137 (2018)

73. Yücebalkan, B.: Digital leadership in the context of digitalization and digital transformations. Current Academic Studies in Social Science 1, 489-505 (2018)

74. Goethals, G. R., Sorenson, G., Burns J.: Leadership in the digital age. Sage Publications, London (2004)

75. Bennis, W.: Leadership in a digital world embracing transparency and adaptive capacity. MIS Q. 37, 635-636 (2013)

76. Reinhardt, K., Lueken, S.: Digital Leadership Exzellenz- Kompetenzmodell für erfolgreiche Führung im digitalen Zeitalter. In: Hartmann, M. (ed.) Impulse für digitale Lösungen: Empfehlungen für Kleine und Mittlere Unternehmen, pp. 35-45. Berliner Wissenschafts-Verlag, Berlin (2018)

77. Zeike, S., Bradbury, K., Lindert, L., Pfaff, H.: Digital Leadership Skills and Associations with Psychological Well-Being. Int. J. Environ. Res. Public Health 16, 1-12 (2019)

78. Sultan, Y. H., Suhail, K. S.: The impact of significant factors of digital leadership on gamification marketing strategy. Int. J. Adv. Res. Dev. 4, 29-33 (2019)

79. Weisman, R.: A Leadership Approach to Successful Digital Transformation Using Enterprise Architecture. University of Ottawa, Ottawa (2019)

80. Weill, P., Wörner, S. L., González, F.: Is Your Company a Digital Leader or a Digital Laggard? MIT Sloan CISR XVII, 1-4 (2017)

81. Trompenaars, F., Woolliams, P.: Going Digital Internationally. Organ. Dev. J. 34, 11-35 (2016)

82. Lucas-Nülle, T.: Digital Leadership. In: Dahm, M. H., Thode, S. (ed.) Strategie und Transformation im digitalen Zeitalter, pp. 119-134. Springer, Wiesbaden (2019)

83. Mangelmann, R.: Digitale Transformation in der Finanzbranche - Auswirkungen neuer Technologien und eines veränderten Kundenverhaltens auf Geschäftsmodell und Unternehmensführung. In: Petry, T. (ed.) Digital Leadership, pp. 129-150. Haufe Lexware GmbH, Freiburg im Breisgau (2016)

84. Jesse, N.: Organizational Evolution - How Digital Disruption Enforces Organizational Agility. IFAC-PapersOnLine 51, 486-491 (2018)

85. Wang, C., Cardon, P. W.: The networked enterprise and legitimacy judgments: why digital platforms need leadership. J. Bus. Strat. 40, 33-39 (2019)

86. Hearsum, S.: How to develop digital leadership capability. Strategic HR Review 14, 208$210(2015)$ 
87. Schirmer, H.: Entwicklung von Digitalkompetenzen und Führungskultur im Zeitalter der Digitalen (r)Evolution - Darstellung am Beispiel Continental. In: Petry, T. (ed.) Digital Leadership, pp. 355-372. Haufe Lexware GmbH, Freiburg im Breisgau (2016)

88. Citrin, J., Neff, T.: Digital Leadership. Organizations \& people 18, 42-50 (2000)

89. Bohlen, W.: Digital Leadership - Wie verändert die Digitalisierung die Mitarbeiterführung und was müssen Personalmanager bereits heute tun? In: Fürst, R.A. (ed.) Gestaltung und Management der digitalen Transformation, pp. 277-292. Springer, Wiesbaden (2019)

90. Petrucci, T., Rivera, M.: Leading Growth through the Digital Leader. J. Leadersh. Stud. 12, 53-56 (2018)

91. Tanniru, M.: Digital Leadership. Oakland University, Rochester (2017)

92. Temelkova, M.: Skills for digital leadership-Prerequisite for developing high-tech economy. Int. J. Adv. Manag. Soc. Sci. 7, 50-74 (2018)

93. Weiner, J., Tanniru, M., Khuntia, J., Bobryk, D., Naik, M., LePage, K.: Digital leadership in action in a hospital through a real time dashboard system implementation and experience. J. Hosp. Adm. 5, 34 (2016)

94. Bäuchle, R.: Digital Leadership-inwiefern können Objectives and Key Results die bestehenden Herausforderungen der Unternehmensführung bewältigen? Ostfalia Hochschule für angewandte Wissenschaft, Wolfenbüttel (2019)

95. Dorozalla, F., Klus, M. F.: Digital Leadership - Status quo der digitalen Führung. In: Groß, M., Müller-Wiegand, M., Pinnow, D. F. (ed.) Zukunftsfähige Unternehmensführung, pp. 89-103. Springer Fachmedien, Heidelberg (2019)

96. Lorenz, M.: Digitale Führungskompetenz. Springer, Wiesbaden (2018)

97. Borins, S., Brown, D.: Digital Leadership: The Human Face of IT. In: Borins, S., Kernaghan, K., Brown, D., Bontis, N. (ed.) Digital State of the Leading Edge, pp. 277301. University of Toronto Press, Toronto (2007)

98. Creusen, U., Gall, B., Hackl, O.: Digital Leadership. Springer, Wiesbaden (2017)

99. Hensellek, S.: Digital Leadership - Ein Rahmenwerk zur erfolgreichen Führung im digitalen Zeitalter. In: Kollmann, T. (ed.) Handbuch Digitale Wirtschaft, pp. 1-19. Springer Fachmedien, Wiesbaden (2019)

100. Dückert, S.: Leitbild der digitalen Führungskraft. In: Petry, T. (ed.) Digital Leadership, pp. 115-128. Haufe Lexware GmbH, Freiburg im Breisgau (2016)

101. Mihardjo, L. W. W., Rukmana, R. A. N.: Does Digital Leadership Impact Directly or Indirectly on Dynamic Capability: Case on Indonesia Telecommunication Industry in Digital Transformation? J. Soc. Sci. Res. 4, 832-841 (2018)

102. Tardieu, H., Daly, D., Esteban-Lauzán, J., Hall, J., Miller, G.: Leadership—What Is Required of Leaders and Leadership to Achieve Digital Success? In: Tardieu, H., Daly, D. Esteban-Lauzán, J., Hall, J., Miller, G. (ed.) Deliberately Digital, pp. 95-105. Springer, Cham (2020)

103. Banks, G. C., Dionne, S. D., Sayama, H., Schmid Mast, M.: Leadership in the Digital Era: Social Media, Big Data, Virtual Reality, Computational Methods, and Deep Learning. Leadersh. Q. 30, I-II (2019)

104. Crummenerl, C., Seebode, R. O.: Das Geheimnis erfolgreicher digitaler Transformationen - Warum Führung, Befähigung und Kultur den Unterschied machen. In: Petry, T. (ed.) Digital Leadership, pp. 151-186. Haufe Lexware GmbH, Freiburg im Breisgau (2016) 
105. Rüth, R., Netzer, T.: The key elements of cultural intelligence as a driver for digital leadership success. Leadership, Education, Personality: An Interdisciplinary Journal 1, 1-6 (2020) 